\title{
A Study on the Number of Jumps and Jump Height in Volleyball: From a Mock Game of College Men Players
}

\author{
Yuki Mori' ${ }^{1}$, Yuta Yamada ${ }^{2}$, Sayuri Umezaki ${ }^{3}$, Noriyuki Kida ${ }^{4}$, Teruo Nomura ${ }^{4}$ \\ ${ }^{1}$ Sonoda Women's University, Amagasaki, Japan \\ ${ }^{2}$ Daido University, Nagoya, Japan \\ ${ }^{3}$ Tenri University, Tenri, Japan \\ ${ }^{4}$ Kyoto Institute of Technology, Kyoto, Japan \\ Email: moriyuki.0630@gmail.com
}

How to cite this paper: Mori, Y., Yamada, Y., Umezaki, S., Kida, N., \& Nomura, T. (2022). A Study on the Number of Jumps and Jump Height in Volleyball: From a Mock Game of College Men Players. Advances in Physical Education, 11, 1-10. https://doi.org/10.4236/ape.2022.121001

Received: November 6, 2021

Accepted: January 9, 2022

Published: January 12, 2022

Copyright (c) 2022 by author(s) and Scientific Research Publishing Inc. This work is licensed under the Creative Commons Attribution International License (CC BY 4.0).

http://creativecommons.org/licenses/by/4.0/

\begin{abstract}
The purpose of this study was to determine jump height and number of jumps during a five-set mock college men's volleyball game using VERT, a jump measurement device. Results were as follows. 1) There was no significant difference in jump height between sets for SJ, TJ, and SPJ. For SJ and BJ, $\mathrm{S}$ and $\mathrm{OH}$ were significantly higher than $\mathrm{MB}$. For each jump type, approximately $65 \%$ to $90 \%$ of jumps were at maximum height, suggesting that players did not always perform at maximum output. 2) The number of jumps per set was 12.7 - 16.3 times for $\mathrm{OH}, 18.5$ - 23 times for $\mathrm{MB}$, and 23 - 32 times for $\mathrm{S}$ in a 25-point match, and 14.7 times for $\mathrm{OH}, 15.5$ times for $\mathrm{MB}$, and 19 times for $S$ in a 15-point match. 3) There was no drop in maximum reach or vertical jump height at the end of the sets.
\end{abstract}

\section{Keywords}

Volleyball, Number of Jumps, Jump Height, VERT

\section{Introduction}

Height at the net is an advantage in the sport of volleyball because the game depends on being able to attack and defend against opponents over the net. Particularly for the offensive technique of spiking and the defensive technique of blocking, jump height is an important factor in addition to the player's height. In fact, jump ability has been reported to have a significant impact on wins and losses (Fukuda et al., 1987; Kurokawa, 2000; Okano \& Tanigawa, 2016). Height is clearly an important aspect of volleyball, and there have been several studies 
focused on jump height and jump motion. Research trends are summarized below under the categories of jump height and number of jumps.

Studies on jump height have focused on the relationship between jump motion and high contact point as well as changes in jump height measurements. With respect to the former, Takanashi (2018) focused on spikes and investigated the effectiveness of the three-step run-up and appropriate step width. Another study of competitive college women spikers showed significantly high values for jump height and knee joint torque (Muramoto et al., 2014). With respect to the latter topic, Wnorowski et al. (2013) reported that game time jump height among top men players in Poland fluctuated between $77-90 \%$ of maximum values, and among top women athletes in Argentina, it was reported that there was no decrease in post-match maximum jump height (Esper, 2003).

Like jump height, jump number has also been studied both in Japan and abroad (Esper, 2003; Lima et al., 2019; Okano \& Tanigawa, 2016). In all these studies, with some differences by nationality, measurements were taken during actual matches with top-level men players. Across all studies, the number of jumps was highest in order by position for setter, middle blocker, and outside hitter, with approximately 12 to 32 jumps per set (Esper, 2003; Lima et al., 2019; Okano \& Tanigawa, 2016).

Recent advances in measurement technology have made it possible to conduct simple measurements of jump motion as well. Several studies have relied on VERT (VERT Wearable Jump Monitor) with a built-in accelerometer to measure the number of jumps and jump height (Esper, 2003; Lima et al., 2019; Sheppard \& Gabbett, 2009). VERT can be synced with iPad applications through Bluetooth so that a player's number of jumps and jump height can be measured in real time. It is also used to track and manage training to prevent player injury (Benson et al., 2020; Skazalski et al., 2018a). The reliability of VERT measurements for the number of jumps and jump height has been verified in comparison with video analysis and observed data (Charlton et al., 2017; Mahmoud et al., 2015; Skazalski et al., 2018b). Although VERT has been adopted by some corporate sports teams in Japan, there do not appear to be any academic assessments of its usefulness.

Most research on jumps in volleyball has centered on top athletes. The few studies involving youth players (Borges et al., 2017) have not had any applications in coaching and training. VERT analysis of jump type and jump height has revealed that jump height does not vary among top athletes even after playing multiple sets (Lima et al., 2019), but in establishing jump indices for the sport, it would be useful to determine whether the same findings apply with a wider scope of athletes that includes lower-level amateur players.

The purpose of this study, therefore, is to use VERT with college men volleyball players to analyze jump height and the number of jumps during a mock game.

\section{Methods}

\subsection{Subjects and Mock Game}

Subjects in this study were six members of the D University volleyball team in 
the Tokai Collegiate Volleyball Association Men's First Division League. Age and physical traits of each subject are shown in Table 1 . The positions played by the six subjects were outside hitter $(\mathrm{OH}: \mathrm{n}=3)$, middle blocker $(\mathrm{MB}: \mathrm{n}=2)$, and setter (S: $n=1)$. Subjects gave prior consent to participation in this study and the use of data after receiving an oral explanation of the purpose and intent of the research and the risk of related injury. This study was conducted with the approval (approval number: 2021-32) of the Institutional Review Board of Kyoto Institute of Technology.

The mock game in this study consisted of a five-set match played at the school. There were 558 jumps recorded in total using sample data from 25-point matches for the first through fourth sets, and a 15-point match for the final set.

\subsection{Measurement Categories and Methodology}

1) Morphometrics

Morphometric items were height, single hand finger reach, and body weight. Finger reach was measured from the fingertip to the floor with the dominant arm extended straight up from a standing upright position using a vertical jump scale (Swift Yardstick). Body weight was measured using a digital scale (DC-430A, TANITA).

2) Maximum reach measurement

Before and after the mock game and between each set, maximum reach was measured three times each for spike jump and vertical jump using VERT (VERT Coach, VERT Wearable Jump Monitor).

3) Jump measurement

Subjects attached the VERT device to their shirt collars during the mock game and data was collected on jump type, the number of jumps, and jump height for each position per set. The number of jumps and jump height data was collected from VERT while the associated jump type was identified using video footage taken from above the end line. Jump type was visually confirmed and categorized by three volleyball players with ten or more years of experience and one sports science expert with over 20 years of volleyball coaching and research experience. Four jump type categories were adopted from the eight categories defined by

Table 1. Subject physical traits and positions.

\begin{tabular}{|c|c|c|c|c|c|c|c|c|}
\hline Player & Position & Age & Height (m) & $\begin{array}{c}\text { Body weight } \\
\text { (kg) }\end{array}$ & $\begin{array}{l}\text { Standing } \\
\text { reach }(\mathrm{m})\end{array}$ & $\begin{array}{l}\text { Highest spike } \\
\text { touch }(\mathrm{m})\end{array}$ & $\begin{array}{l}\text { Running jump } \\
\text { (m) }\end{array}$ & $\begin{array}{c}\text { Vertical jump } \\
\text { (m) }\end{array}$ \\
\hline A & $\mathrm{OH}$ & 18 & 1.84 & 72.6 & 2.33 & 3.19 & 0.86 & 0.66 \\
\hline B & $\mathrm{OH}$ & 21 & 1.78 & 74.4 & 2.30 & 3.06 & 0.76 & 0.65 \\
\hline $\mathrm{C}$ & $\mathrm{OH}$ & 20 & 1.80 & 82.3 & 2.28 & 3.11 & 0.83 & 0.78 \\
\hline $\mathrm{D}$ & $\mathrm{MB}$ & 21 & 1.85 & 80.0 & 2.37 & 3.25 & 0.88 & 0.74 \\
\hline $\mathrm{E}$ & $\mathrm{MB}$ & 19 & 1.88 & 66.0 & 2.44 & 3.26 & 0.82 & 0.66 \\
\hline $\mathrm{F}$ & $S$ & 20 & 1.70 & 57.4 & 2.18 & 3.05 & 0.87 & 0.70 \\
\hline
\end{tabular}


Lima et al. (2019): spike jump (SPJ), block jump (BJ), serve jump (SJ), and toss jump (TJ). The remaining four categories of reception, simulation, celebration, and null were excluded from analysis due to low jump height and deemed lower impact on performance. The mock game consisted of four 25-point rally sets and a final 15-point rally set. Subjects warmed up prior to the mock game with pass, pair receive, toss, spike, and serve practice.

\subsection{Statistical Processing}

The results of analysis were divided by set and position with calculated means and standard deviations. Unpaired one-way factorial ANOVA was used to test for differences in the mean values of jump height by jump type, jump height by set and position for each jump type, and jump height by jump type for each position. Multiple comparison tests were then performed using Tukey's HSD method, and the value of $\eta^{2}$ was calculated as effect size. Paired one-way repeated measures ANOVA was used for the maximum reach and vertical jump measured before the start of the mock game and after the end of each set, and the value of $\eta^{2} \mathrm{p}$ was calculated as effect size. In all analyses of variance, $\mathrm{OH}$ and $\mathrm{MB}$ positions (not S) were included in analysis for SJ, and the difference in means was tested by unpaired t-test. The value of $d$ was calculated as effect size. IBM SPSS Ver.24 was used for statistical processing, and the significance level was set at $5 \%$.

\section{Results}

Table 2 shows jump height per set for each jump type. Analysis of variance showed that there was significant main effect on jump height per set only for BJ $\left(\mathrm{F}(4,185)=2.942, p=0.022, \eta^{2}=0.060\right)$ and not for SJ $(\mathrm{F}(4,81)=1.494, p=$ $\left.0.212, \eta^{2}=0.069\right), \mathrm{TJ}\left(\mathrm{F}(4,96)=1.326, p=0.266, \eta^{2}=0.053\right)$, and SPJ $(\mathrm{F}(4$, $\left.176)=0.456, p=0.768, \eta^{2}=0.011\right)$. Multiple comparison test results showed that the second set was significantly higher than the third set $(p=0.026)$.

Table 3 shows the jump height per position for each jump type. Analysis of variance for SJ and BJ showed a significant main effect on jump height per position

Table 2. Jump height per set for each jump type.

\begin{tabular}{|c|c|c|c|c|c|c|c|c|c|c|c|c|c|c|c|}
\hline \multirow{3}{*}{$\begin{array}{c}\text { Type } \\
\text { of } \\
\text { jump }\end{array}$} & \multicolumn{3}{|c|}{ First set } & \multicolumn{3}{|c|}{ Second set } & \multicolumn{3}{|c|}{ Third set } & \multicolumn{3}{|c|}{ Fourth set } & \multicolumn{3}{|c|}{ Fifth set } \\
\hline & Number & Jump & neight & Number & Jump & neight & Number & Jump & neight & Number & Jump & neight & Number & Jump & height \\
\hline & Occurrence & $\begin{array}{c}\mathrm{M} \\
(\mathrm{m})\end{array}$ & $\begin{array}{l}\text { SD } \\
(\mathrm{m})\end{array}$ & Occurrence & $\begin{array}{c}\mathrm{M} \\
(\mathrm{m})\end{array}$ & $\begin{array}{l}\mathrm{SD} \\
(\mathrm{m})\end{array}$ & Occurrence & $\begin{array}{c}\mathrm{M} \\
(\mathrm{m})\end{array}$ & $\begin{array}{l}\text { SD } \\
(\mathrm{m})\end{array}$ & Occurrence & $\begin{array}{c}\mathrm{M} \\
(\mathrm{m})\end{array}$ & $\begin{array}{l}\text { SD } \\
(\mathrm{m})\end{array}$ & Occurrence & $\begin{array}{c}\mathrm{M} \\
(\mathrm{m})\end{array}$ & $\begin{array}{l}\mathrm{SD} \\
(\mathrm{m})\end{array}$ \\
\hline Serve & 18 & 0.48 & 0.18 & 23 & 0.48 & 0.15 & 14 & 0.40 & 0.17 & 16 & 0.45 & 0.18 & 15 & 0.55 & 0.14 \\
\hline Set & 24 & 0.41 & 0.11 & 19 & 0.38 & 0.11 & 23 & 0.44 & 0.11 & 24 & 0.44 & 0.10 & 11 & 0.40 & 0.12 \\
\hline Spike & 40 & 0.58 & 0.15 & 33 & 0.59 & 0.13 & 43 & 0.61 & 0.12 & 38 & 0.59 & 0.11 & 27 & 0.61 & 0.12 \\
\hline Block & 47 & 0.54 & 0.11 & 32 & 0.57 & 0.08 & 33 & 0.49 & 0.11 & 37 & 0.50 & 0.11 & 41 & 0.53 & 0.09 \\
\hline
\end{tabular}


Table 3. Jump height per position for each jump type.

\begin{tabular}{|c|c|c|c|c|c|c|c|c|c|c|c|c|c|c|c|}
\hline \multirow{3}{*}{$\begin{array}{l}\text { Type } \\
\text { of } \\
\text { jump }\end{array}$} & \multicolumn{5}{|c|}{ Middle blocker } & \multicolumn{5}{|c|}{ Setter } & \multicolumn{5}{|c|}{ Outside spiker } \\
\hline & \multirow{2}{*}{$\begin{array}{c}\begin{array}{c}\text { Number } \\
\text { of jumps }\end{array} \\
\text { Occurrence }\end{array}$} & \multicolumn{2}{|c|}{ Jump height } & \multicolumn{2}{|c|}{$\begin{array}{c}\text { Jump } \\
\text { height ratio }\end{array}$} & \multirow{2}{*}{$\begin{array}{l}\begin{array}{c}\text { Number } \\
\text { of jumps }\end{array} \\
\text { Occurrence }\end{array}$} & \multicolumn{2}{|c|}{ Jump height } & \multicolumn{2}{|c|}{$\begin{array}{c}\text { Jump } \\
\text { height ratio }\end{array}$} & \multirow{2}{*}{$\begin{array}{l}\text { Number } \\
\text { of jumps }\end{array}$} & \multicolumn{2}{|c|}{ Jump height } & \multicolumn{2}{|c|}{$\begin{array}{c}\text { Jump } \\
\text { height ratio }\end{array}$} \\
\hline & & $\begin{array}{l}\mathrm{M} \\
(\mathrm{m})\end{array}$ & $\begin{array}{l}\mathrm{SD} \\
(\mathrm{m})\end{array}$ & $\begin{array}{c}M \\
(\%)\end{array}$ & $\begin{array}{l}\mathrm{SD} \\
(\%)\end{array}$ & & $\begin{array}{l}M \\
(\mathrm{~m})\end{array}$ & $\begin{array}{l}\mathrm{SD} \\
(\mathrm{m})\end{array}$ & $\begin{array}{c}M \\
(\%)\end{array}$ & $\begin{array}{l}\mathrm{SD} \\
(\%)\end{array}$ & & $\begin{array}{l}\mathrm{M} \\
(\mathrm{m})\end{array}$ & $\begin{array}{l}\mathrm{SD} \\
(\mathrm{m})\end{array}$ & $\begin{array}{c}M \\
(\%)\end{array}$ & $\begin{array}{l}\mathrm{SD} \\
(\%)\end{array}$ \\
\hline Serve & 31 & 0.29 & 0.04 & 80.6 & 9.5 & 14 & 0.59 & 0.05 & 88.1 & 7.6 & 41 & 0.57 & 0.12 & 76.9 & 15.9 \\
\hline Set & 0 & 0.00 & 0 & - & - & 101 & 0.42 & 0.11 & 65.8 & 17.2 & 0 & 0.00 & 0.00 & - & - \\
\hline Spike & 78 & 0.62 & 0.10 & 82.9 & 13.4 & 0 & 0.00 & 0.00 & - & - & 103 & 0.57 & 0.14 & 71.5 & 17.6 \\
\hline Block & 90 & 0.49 & 0.10 & 68.7 & 14.1 & 25 & 0.60 & 0.08 & 89.6 & 11.7 & 75 & 0.55 & 0.09 & 79.3 & 14.8 \\
\hline
\end{tabular}

Note: Jump ratio (\%) was calculated from the maximum jump height of each subject for each jump type.

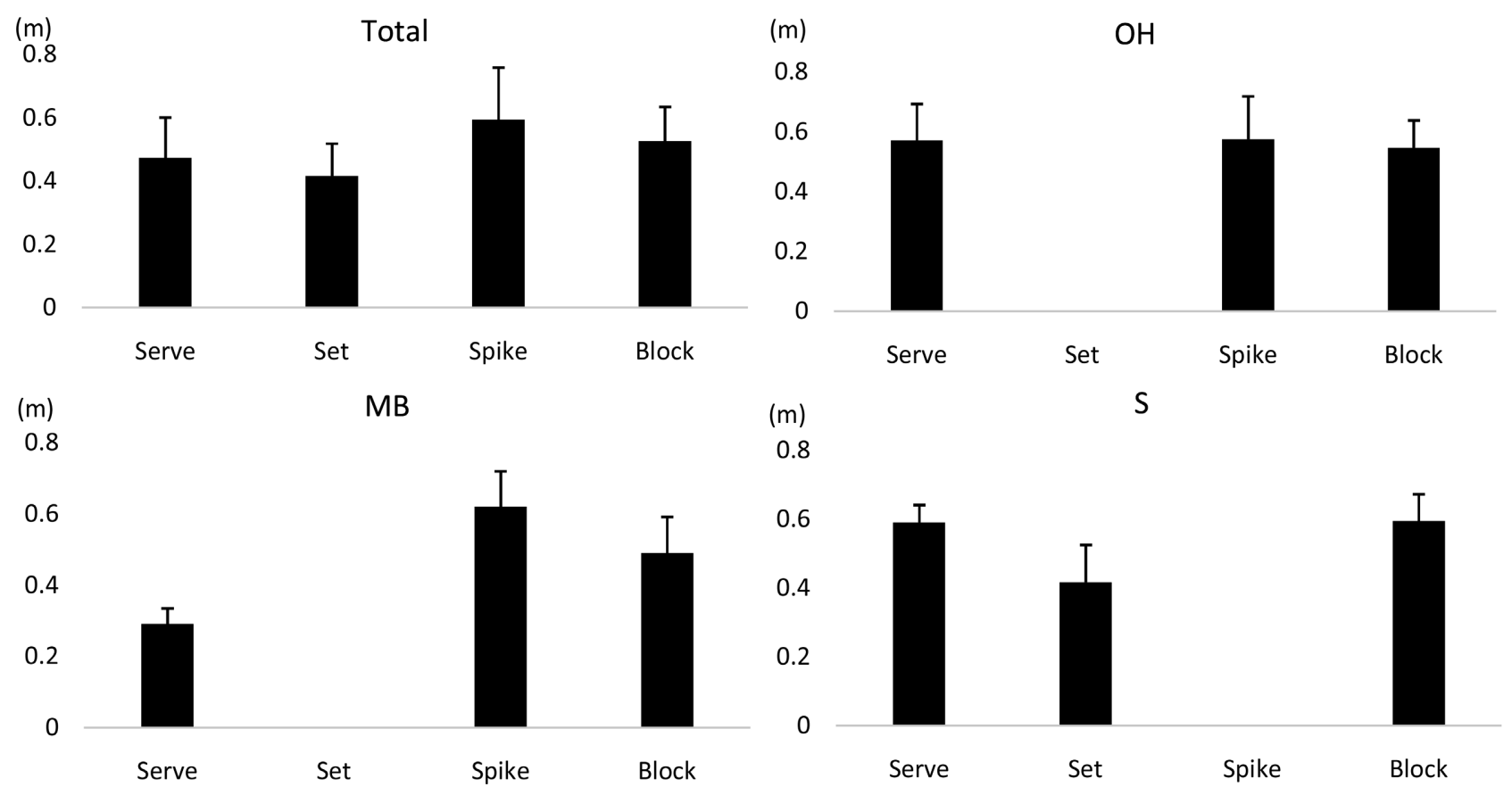

Figure 1. Jump height for each jump type and jump height for each jump type for each position.

for both (SJ: $\left.F(2,83)=97.190, p<0.001, \eta^{2}=0.701\right)$; BJ: $F(2,187)=14.737, \mathrm{p}$ $\left.<0.001, \eta^{2}=0.137\right)$. Multiple comparison tests showed that for SJ, $\mathrm{S}$ and $\mathrm{OH}$ were significantly higher than $\mathrm{MB}(p<0.001$, respectively), and for $\mathrm{BJ}, \mathrm{S}$ ( $p<$ $0.001)$ and $\mathrm{OH}(p=0.001)$ were significantly higher than MB. An unpaired t-test for SPJ showed that MB was significantly higher than $\mathrm{OH}(t(179)=2.374, p=$ $0.019, d=0.360)$.

Figure 1 shows the jump height for each jump type and the jump height for each jump type at each position. Analysis of variance for jump height for each jump type showed a significant main effect for jump type $(F(3,554)=49.786, p$ $\left.<0.001, \eta^{2}=0.213\right)$. Multiple comparison tests showed that SPJ, BJ, SJ, and TJ had the highest values, in order. Analysis of variance for jump height by jump 
type for each position showed a significant main effect (for jump type) for $\mathrm{MB}$ and S (MB: $F(2,196)=97.190, p<0.001, \eta^{2}=0.587$; $: F(2,137)=44.043, p<$ $\left.0.001, \eta^{2}=0.392\right)$. The results of multiple comparison tests showed that for the MB position, SPJ, BJ, and SJ were higher $(p<0.001$ each). For the $\mathrm{S}$ position, SJ and $\mathrm{BJ}$ were significantly higher than $\mathrm{TJ}(p<0.001$ each). There was no significant main effect for $\mathrm{OH}\left(F(2,216)=1.239, p=0.292, \eta^{2}=0.012\right)$.

Jump height ratios calculated from the maximum jump height of each subject for each jump type were MB $80.6 \% \pm 9.5 \%$, S $88.1 \% \pm 7.6 \%$, and $\mathrm{OH} 76.9 \% \pm$ $15.9 \%$ for SJ, S $65.8 \% \pm 17.2 \%$ for TJ, MB $82.9 \% \pm 13.4 \%$ and $\mathrm{OH} 71.5 \% \pm 17.6 \%$ for SPJ, and MB $68.7 \% \pm 14.1 \%$, S $89.6 \% \pm 11.7 \%$, and $\mathrm{OH} 79.3 \% \pm 14.8 \%$ for BJ (Table 3).

The total number of jumps by position was OH 219 times, MB 199 times, and S 140 times. The total number of jumps by position was 219 times for $\mathrm{OH}, 199$ times for $\mathrm{MB}$, and 140 times for $\mathrm{S}$. The number of jumps per player was 73 times for $\mathrm{OH}, 99.5$ times for $\mathrm{MB}$, and 140 times for $\mathrm{S}$. The number of jumps per set was 12.7 - 16.3 times for $\mathrm{OH}, 18.5$ - 23.0 times for $\mathrm{MB}$, and 23 - 32 times for $\mathrm{S}$ in the 25-point match, and 14.7 times for $\mathrm{OH}, 15.5$ times for $\mathrm{MB}$, and 19 times for $S$ in the 15-point match.

Table 4 shows the maximum reach and vertical jump height before the start of the mock game and after each set. Analysis of variance showed that there was no significant main effect on jump height per set for either maximum reach or vertical jump height (maximum reach: $F(5,25)=2.597, p=0.050, \eta^{2} \mathrm{p}=0.342$; $S: \mathrm{F}\left(5,(5,25)=2.436, p=0.063, \eta^{2} p=0.328\right)$.

\section{Discussion}

With respect to jump height per set for each jump type, although second set values were significantly higher than the third set for BJ, there was no significant difference for SJ, TJ, and SPJ. This is similar to findings by Lima et al. (2019) as opposed to conflicting findings by Wnorowski et al. (2013) that jump height tended to decrease as more sets were played. This discrepancy may be related to jump height adjustments made by individual players, as noted by Lima et al. (2019). That is, the number of rallies and other circumstances of the match also affect jump height since players need to align their jump height for tosses, spikes, blocks, and other plays than the serve in alignment with their teammates and

Table 4. Maximum reach and vertical jump height before the start of the mock game and after each set.

\begin{tabular}{|c|c|c|c|c|c|c|c|c|c|}
\hline & & Pre & $1^{\text {st }}$ & $2^{\text {nd }}$ & $3^{\text {rd }}$ & $4^{\text {th }}$ & $5^{\text {th }}$ & $\mathrm{p}$ & $\eta^{2} \mathrm{p}$ \\
\hline \multirow{2}{*}{$\begin{array}{l}\text { Highest spike } \\
\text { touch }(\mathrm{m})\end{array}$} & $\mathrm{M}$ & 3.14 & 3.12 & 3.13 & 3.11 & 3.11 & 3.10 & \multirow{2}{*}{0.050} & \multirow{2}{*}{0.342} \\
\hline & SD & 0.11 & 0.09 & 0.09 & 0.09 & 0.07 & 0.07 & & \\
\hline \multirow{2}{*}{$\begin{array}{c}\text { Vertical } \\
\text { jump (m) }\end{array}$} & $\mathrm{M}$ & 0.70 & 0.70 & 0.69 & 0.69 & 0.69 & 0.68 & \multirow{2}{*}{0.063} & \multirow{2}{*}{0.328} \\
\hline & SD & 0.05 & 0.04 & 0.05 & 0.06 & 0.05 & 0.04 & & \\
\hline
\end{tabular}


opponents. Jump height ratios calculated from the maximum jump height of each subject for each jump type showed that individual jump heights ranged from $76.9 \%$ to $88.1 \%$ for SJ and $68.7 \%$ to $89.6 \%$ for BJ. In other words, for each type of jump, players jumped at about $65 \%$ to $90 \%$ of their maximum jump height and did not always jump at their maximum output.

With respect to jump height per position for each jump type, $\mathrm{S}$ and $\mathrm{OH}$ were significantly higher than $\mathrm{MB}$ for SJ and BJ, similar to results reported by Lima et al. (2019). One explanation for why MB was lower than other positions for SJ and $\mathrm{BJ}$ is finger reach. Finger reach was $218 \mathrm{~cm}$ for $\mathrm{S}, 230.3 \pm 2.5 \mathrm{~cm}$ for $\mathrm{OH}$, and $240.5 \pm 4.9 \mathrm{~cm}$ for $\mathrm{MB}$, with $\mathrm{MB}$ being the highest. Higher finger reach makes it possible to perform appropriate jumps using less power (Lima et al., 2019). In contrast to previous findings that $\mathrm{OH}$ was significantly higher than $\mathrm{MB}$ for SPJ (Lima et al., 2019), this study found that MB was significantly higher than $\mathrm{OH}$. Likewise, jump height ratios against maximum jump height of $71.5 \%$ for $\mathrm{OH}$ and $82.9 \%$ for $\mathrm{MB}$ show that $\mathrm{MB}$ was higher. One factor behind this may be that the tempo of the toss for $\mathrm{OH}$ and $\mathrm{MB}$ is different. While $\mathrm{OH}$ can self-adjust jumps against the received ball, since the toss is delivered after the jump for $\mathrm{MB}, \mathrm{MB}$ tends to require both greater jump height and effort.

With respect to jump height for each jump type, the highest values occurred in order of SPJ, BJ, SJ, and TJ. In volleyball, plays near the net are critical and require a high jump height (Kurokawa, 2000; Lima et al., 2019). These results, therefore, were as predicted since SPJ and BJ are both plays that happen close to the net. Results were consistent with the above as well for jump height for each position.

Differences in the number of jumps were examined for each position and its role. In previous studies of top players and top youth players, the number of jumps per set was about 12 - 23 times for $\mathrm{OH}, 18$ - 27 times for $\mathrm{MB}$, and 18 - 32 times for S, with S having the highest number of jumps (Esper, 2003; Lima et al., 2019; Okano \& Tanigawa, 2016; Sheppard \& Gabbett, 2009). Our findings were similar, with 12.7 to 16.3 times for $\mathrm{OH}, 15.5$ to 23.0 times for $\mathrm{MB}$, and 19 to 32 times for S. Considering that use of the jump set increases with higher setter ability and team level (Palao \& Martinez, 2013), we can assume that skill level has an influence on the number of jumps that occur in a game, and that results may differ among elementary and junior/senior high school players. Clarifying the number of jumps in games and practices could contribute to the evaluation of individualized training loads (Lima et al., 2019) as well as individual load management for injury prevention (Benson et al., 2020; Skazalski et al., 2018a).

There was no significant difference in maximum reach and vertical jump height before the start of the mock game and after each set. In contrast, a study of jump height continuity by Muramoto et al. (1983) found that there was a significant decrease in jump height between the first and last of 100 jumps. Another study found with respect to vertical jump endurance that jump height decreases with increased number of jumps and workload (Ichigi, 1982). Further, it has been reported that there is a strong tendency in groups with low athletic ability 
for jump height to decrease consistently as the number of jumps increase, while such tendency is weaker, and a certain level of jump height can be sustained in groups with moderate athletic ability (Ishide, 1990). In this study, the average number of jumps was 79.6 times per player throughout the five sets, that is, less than the number of jumps reported in the previous studies that found decreases in jump height. In addition to the moderate skill level of the subjects in this study, the fact that jump height did not decrease may be therefore also explained in part by the more limited number of jumps. The lack of any decrease in maximum output after the game may have been the result of adjustments made by the players to maintain performance during the game, which in volleyball is characterized by a mixture of instantaneous and endurance elements.

The purpose of this study was to clarify jump height and number of jumps during a mock game using VERT for college men volleyball players. Results indicate that the characteristics of jump height and number of jumps during games are similar between top players and amateur players. Further, this study verified the usefulness of VERT Coach for measuring data in the field, although additional validation with a wider scope of subjects will be required to accumulate more detailed knowledge for practical applications.

\section{Conclusion}

The purpose of this study was to use VERT to determine jump height and the number of jumps during a mock college men's volleyball game. Results were as follows.

1) There was no significant difference in jump height between sets for SJ, TJ, and SPJ. For SJ and BJ, S and $\mathrm{OH}$ were significantly higher than MB. For each jump type, approximately 65 to $90 \%$ of jumps were at maximum height, suggesting that players did not always perform at maximum output. These results matched the findings of Lima et al. (2019).

2) The number of jumps per set was 12.7 - 16.3 times for $\mathrm{OH}, 18.5$ - 23 times for $\mathrm{MB}$, and 23 - 32 times for $\mathrm{S}$. These results matched findings in previous studies (Esper, 2003; Lima et al., 2019; Okano \& Tanigawa, 2016; Sheppard \& Gabbett, 2009).

3) There was no drop in maximum reach or vertical jump height at the end of the sets.

Findings suggest that the characteristics of jump height and number of jumps during a game are similar between top players and amateurs. Although additional verification with a wider range of subjects will be necessary considering that the number of jumps during a game may depend on skill level, the findings of this study will be useful in coaching amateur players.

\section{Conflicts of Interest}

The authors declare no conflicts of interest regarding the publication of this paper. 


\section{References}

Benson, L. C., Tait, T. J., Befus, K., Choi, J., Hillson, C., Stilling, C., Grewal, S., MacDonald, K., Pasanen, K., \& Emery, C. A. (2020). Validation of a Commercially Available Inertial Measurement Unit for Recording Jump Load in Youth Basketball Players. Journal of Sports Sciences, 38, 928-936. https://doi.org/10.1080/02640414.2020.1737360

Borges, T. O., Moreira, A., Bacchi, R., Finotti, R. L., Ramos, M., Lopes, C. R., \& Aoki, M. S. (2017). Validation of the VERT Wearable Jump Monitor Device in Elite Youth Volleyball Players. Biology of Sport, 34, 239-242. https://doi.org/10.5114/biolsport.2017.66000

Charlton, P. C., Kenneally-Dabrowski, C., Sheppard, J., \& Spratford, W. (2017). A Simple Method for Quantifying Jump Loads in Volleyball Athletes. Journal of Science and Medicine in Sport, 20, 241-245. https://doi.org/10.1016/j.jsams.2016.07.007

Esper, A. (2003). Jumps Performed by Female Players during a Volleyball Game. Rey Digit Educ Fisicay Deport, 8. https://www.efdeportes.com/efd58/saltos.htm

Fukuda, T., Watabe, H., \& Minami, M. (1987). Study on In-Situ Continuous Jumping in Volleyball. Bulletin of Faculty of Liberal Arts, Ehime University, 20, 661-672.

Ichigi, A. (1982). 4063 Examination of Jump Endurance. In Japan Society for Physical Education Conference 33rd (p. 296). General Incorporated Association Japan Society for Physical Education.

Ishide, Y. (1990). Study on Sustainability of Jumping Power and Competitive Ability in Volleyball Players (Part 1). Bulletin of Keio Institute of Physical Education, 30, 21-35.

Kurokawa, S. (2000). Achievements of Sports Science That Contribute to Improving the Competitiveness of Volleyball. In The 50th Anniversary of the Japanese Society of Physical Education, Special Committee Edition, 21st Century and Development of Physical Education and Sports Science (Vol. 2, pp. 87-97). Kyorin Shoin Publishers.

Lima, R. F., Palao, J. M., \& Clemente, F. M. (2019). Jump Performance during Official Matches in Elite Volleyball Players: A Pilot Study. Journal of Human Kinetics, 67, 259-269. https://doi.org/10.2478/hukin-2018-0080

Mahmoud, I., Othman, A., Abdelrasoul, E., Stergiou, P., \& Katz, L. (2015). The Reliability of a Real Time Wearable Sensing Device to Measure Vertical Jump. Procedia Engineering, 112, 467-472. https://doi.org/10.1016/j.proeng.2015.07.226

Muramoto, M., Kurita, Y., Takane, S., Takizawa, H., Hirano, Y., Inamura, K., Kose, Y., Tsukamoto, H., \& Kawai, M. (2014). Relationship between Jump Height and Jump Performance of Elite Male Volleyball Players. Volleyball Research, 16, 1-6.

Muramoto, N., Iwanami, R., \& Hamano, M. (1983). Study on Fatigue Curve of Continuous Jump (1st Report). 830 Study on Fatigue Curve of Continuous Jump (1st Report): For Volleyball Players with Different Competitive Abilities. In Japan Society of Physical Education Conference 34th (p. 523). General Incorporated Association Japan Physical Education Society.

Okano, K., \& Tanigawa, S. (2016). A Study on the Jump during the Top-Level Male Volleyball Games. Volleyball Research, 18, 7-31.

Palao, J. M., \& Martinez, S. (2013). Use of Jump Set Regarding Competition Level in Men's Volleyball. SportTK, 2, 43-49.

Sheppard, J. M., \& Gabbett, T. (2009). An Analysis of Playing Positions in Elite Men's Volleyball: Considerations for Competition Demands and Physiologic Characteristics. The Journal of Strength and Conditioning Research, 23, 1858-1866.

https://doi.org/10.1519/JSC.0b013e3181b45c6a 
Skazalski, C., Whiteley R., Hansen, C., \& Bahr, R. (2018a). High Jump Demands in Professional Volleyball-Large Variability Exists between Players and Player Positions. Scandinavian Journal of Medicine \& Science in Sports, 28, 2293-2298.

https://doi.org/10.1111/sms.13255

Skazalski, C., Whiteley R., Hansen, C., \& Bahr, R. (2018b). A Valid Reliable Method to Measure Jump-Specific Training and Competition Load in Elite Volleyball Players. Scandinavian Journal of Medicine \& Science in Sports, 28, 1578-1585. https://doi.org/10.1111/sms.13052

Takanashi, Y. (2018). Various Approaches' Influence on Height of Volleyball Spike Jump. Kyoto Sangyo University Review Natural Science Series, 45, 171-184.

Wnorowski, K., Aschenbrenner, P., Skobecki, J., \& Stech, M. (2013). An Assessment of a Volleyball Player's Loads in a Match on the Basis of the Number and Height of Jumps Measured in Real-Time Conditions. Baltic Journal of Health and Physical Activity, 5, 199-206. https://doi.org/10.2478/bjha-2013-0019 